\title{
Mathematics Houses and Their Impact on Mathematics Education
}

\author{
Ali Rejali, Peter Taylor, Yahya Tabesh, Jérôme Germoni \\ and Abolfazl Rafiepour
}

Since 1999, teams of the Iranian high school teachers and university faculty developed and promoted the idea of Mathematics Houses. A "Math House" is a community center that aims to provide a learning environment and opportunities for students and teachers at all levels to experience deeper understanding of mathematical concepts and develop creativity through teamwork and cooperation to work on real-life problems through (Barbeau \& Taylor, 2009). The first Mathematics House was established in Isfahan, Iran, as an NGO for the occasion of Mathematics Year 2000. Mathematics Houses have been developed in more than 30 cities in Iran under the Iranian Union of Math Houses.

Mathematics Houses have also been established in other places around the world, for example at the Maison des Mathématiques et de l'Informatique (Lyon, France), La Maison des Maths (Quaregnon, Belgium), Mathematicum (Giessen, Germany), and the Archimedes Premises (Belgrade, Serbia).

Goal of the Discussion Group: Introduce Mathematics Houses and similar institutions around the world, discuss their effects on mathematics education and their important impacts on promoting teamwork and popularizing mathematics, and look for some new ways of cooperation and exchange of experiences.

Structure of the Discussion Group: First day of the program started with an introduction by Peter Taylor, followed by a talk by Ali Rejali introducing Isfahan Mathematics House. Christian Mercat then introduced the House for Mathematics and Informatics in France and Abolfazl Rafiepour discussed on developing Mathematics Houses in Iran, followed by a discussion session chaired by Peter Taylor. The second day started with a talk on content development in Mathematics Houses by Yahya Tabesh, which was then followed by panel discussions on goals, strategies, and programs for Mathematics Houses chaired by Peter Taylor with Christian Mercat, Yahya Tabesh, and Abolfazl Rafiepour as the panel members.

\footnotetext{
A. Rejali ( ()

Isfahan University of Technology, Isfahan, Iran

e-mail: a_rejali@cc.iut.ac.ir; a.rejali@yahoo.com

(C) The Author(s) 2017

G. Kaiser (ed.), Proceedings of the 13th International Congress on Mathematical

Education, ICME-13 Monographs, DOI 10.1007/978-3-319-62597-3_103
} 
The closing session consisted of discussions about conclusion and future works and was chaired by Ali Rejali.

Outcome: Exchanging experiences globally, establishment of an International Network of Mathematics Houses and promotion of establishing Mathematics Houses in other regions worldwide.

\section{Reference}

Barbeau, E. J., \& Taylor, P. J. (Eds.). (2009). Challenging mathematics in and beyond the classroom, the 16th ICMI study, new ICMI study series. New York: Springer.

Open Access Except where otherwise noted, this chapter is licensed under a Creative Commons Attribution 4.0 International License. To view a copy of this license, visit http://creativecommons. org/licenses/by/4.0/.

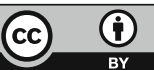

